NASZA DERMATOLOGIA Onlin OUR DERMATOLOGY Online

Source of Support: Nil

Competing Interests: None

\section{UNUSAL PRESENTATION OF GRANULOMA ANNULARE RESTRICTED OVER THE PALMS: A RARE CASE PRESENTATION}

\author{
Snehal Lunge ${ }^{1}$, Pradeep Mahajan ${ }^{2}$, Neeta Gokhale ${ }^{2}$, Renny Pinto $^{2}$ \\ ${ }^{1}$ Department of Dermatology, Venereology and Leprosy, Jawaharlal Nehru Medical \\ College, Nehru Nagar, Belgaum, Karnataka, India \\ ${ }^{2}$ Department of Dermatology, Venereology and Leprosy, Shrimati Kashibai Navale \\ Medical College \& General Hospital, Narhe, Pune, Maharashtra, India
}

Corresponding author: Ass. Prof. Snehal Lunge

drsnehallunge@gmail.com

\begin{abstract}
We report a patient with erythematous firm papules and nodules over palms. Histological examination, which identified epidermis showed marked hyperkeratosis and dermis with perivascular lympho-histiocytic infiltrate which also extended in between the collagen bundles with occasional multinucleated giant cells and mucin deposition. This established the diagnosis of Granuloma Annulare (GA). This is an unusual presentation because of the late onset, uncommon localization, and absence of classical lesions of GA elsewhere.
\end{abstract}

Key words: Granuloma Annulare; the interstitial pattern of GA; hydroxychloroquine

Cite this article:

Snehal Lunge, Pradeep Mahajan, Neeta Gokhale, Renny Pinto. Unusal presentation of granuloma annulare restricted over the palms: a rare case presentation. Our Dermatol Online. 2014; 5(1): 45-47.

\section{Introduction}

Granuloma Annulare (GA) has been described in several morphologic forms i.e. annular disseminated, subcutaneous, papular and perforating. Although GA is primarily a disease of children and young adults, it has been reported in virtually all age groups. Females are affected twice as often as males, and familial occurrence is rare. No associated systemic sequel are present, and laboratory evaluation is usually normal. Disseminated GA is considered a distinct entity from the localised form because of the possible association with diabetes, a later age of onset, and rare spontaneous resolution. Therapy is usually disappointing. Various forms of therapies that have been reported to have a variable response are topical and intralesional steroids, dapsone, retinoids, niacinamide, chloroquine, colchicine, cryotherapy, electrodessication and X-ray therapy [1].

Though GA is a common disorder in dermatologic daily practice, its localization only over palms is uncommon and is infrequently reported in the literature. In most cases it is associated with classical lesions of GA elsewhere, when the diagnosis is relatively easy [2]. In case of isolated lesions a high degree of clinical suspicion of GA is required and histopathology is of vital importance in making the diagnosis. We recently studied an adult patient with lesions of GA at atypical site, absence of classical lesions of GA elsewhere and diagnosis made only on histopathological examination.

\section{Case Report}

A 65 years married male patient known stable hypertensive presented with multiple, erythematous, mildly tender, firm papules and nodules on palms of two months duration (Fig. 1). Patient did not have similar lesions or hypoaesthetic patches or any other skin lesion elsewhere. There was no history of drug intake, fever, joint pains, mucosal or genital lesions, sore throat or cough. General and systemic examination of the patient was normal. Various clinical possibilities considered were erythema multiforme, erythema elevatum diutinum, drug reactions, vasculitis / urticarial vasculitis, secondary syphilis, erythromelalgia, sarcoidosis etc.

Routine investigations, VDRL, RA factor and investigations for diabetes, connective tissue disorders and thyroid disorders were all normal. A punch biopsy of one of the papules over left palm showed epidermis with marked hyperkeratosis. The dermis had hypercellularity and inflammation likened to Busy Dermis, perivascular lympho-histiocytic infiltrate with occasional multinucleated giant cells. This lympho-histiocytic infiltrate was extending in between the collagen bundles which appeared to be separated from each other. 
Special stain for mucin in the form of alcian blue stain at $\mathrm{pH}$ 2.5 showed bluish mucin separating pink collagen bundles in dermis (Fig. 2,3). There was no frank necrobiosis or vasculitis in the dermis.

These histologic findings made the final diagnosis of
Interstitial Granuloma Annulare. The patient was treated with hydroxychloroquine sulphate $400 \mathrm{mg}$ /day as the lesions were painful. At the end of 1 month remarkable clinical improvement was observed (Fig. 4) and the patient did not experience any adverse drug reactions. He is being followed till today.

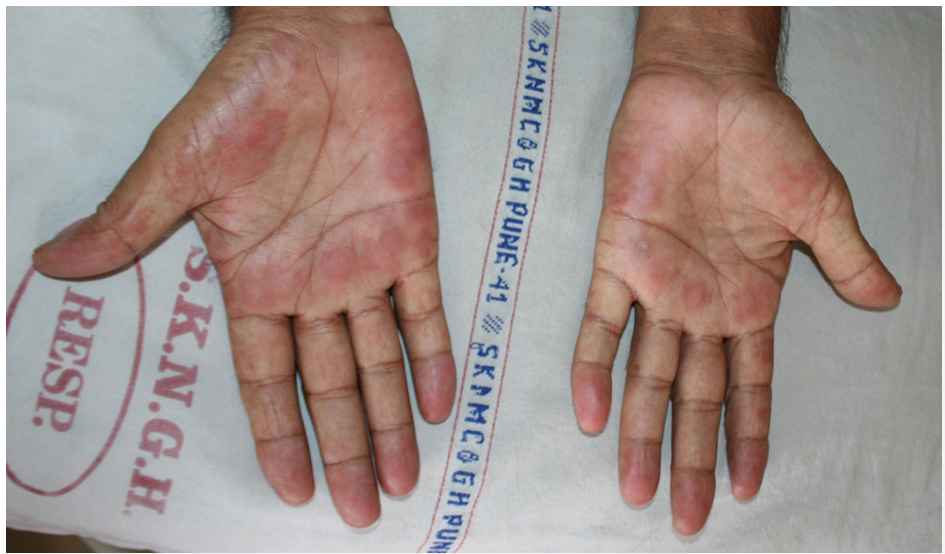

Figure 1. Erythematous papules over palms before treatment.

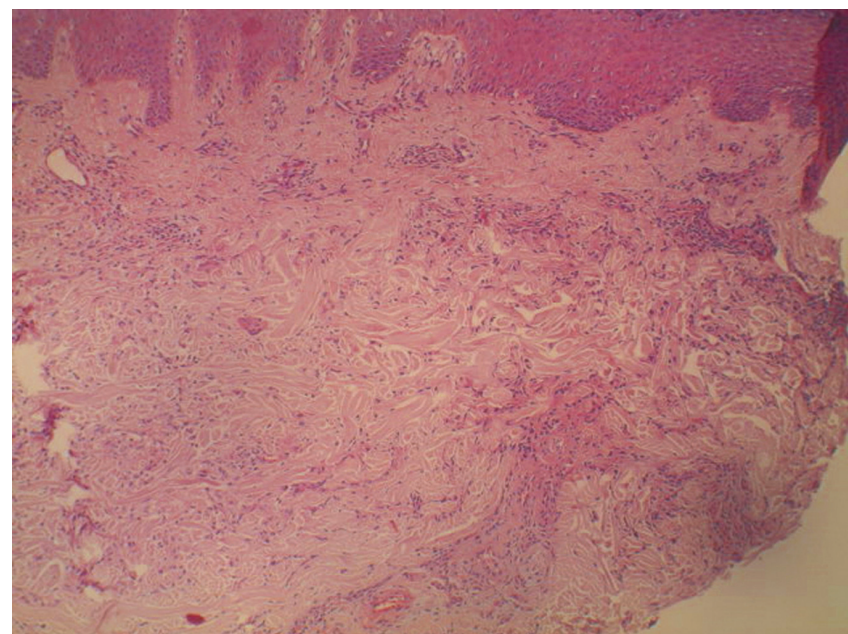

Figure 2. Lympho-histiocytic infiltrate extending in between the collagen bundles which appeared to be separated from each other.

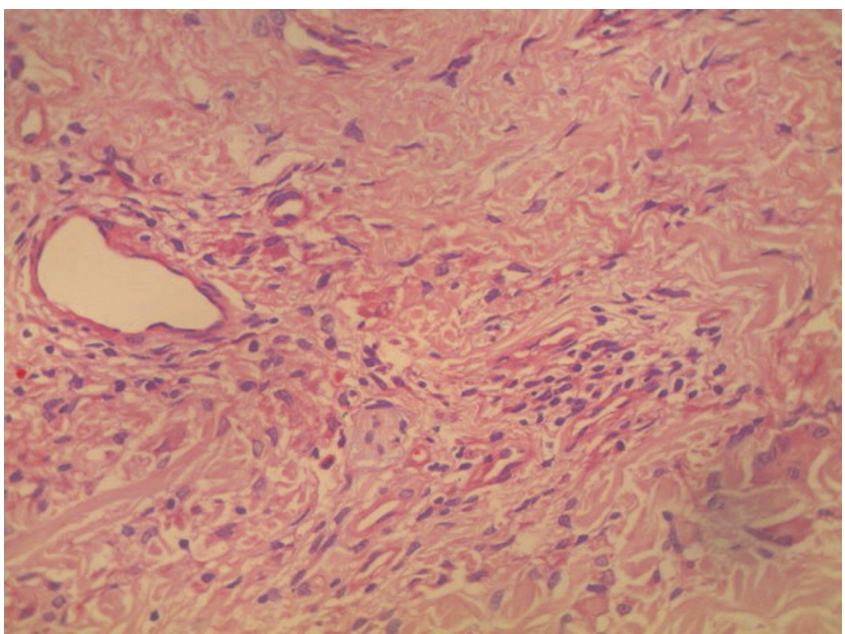

Figure 3. Inflammatory infiltrate composed of lymphocytes, histiocytes and giant cells (H\&E original magnification $\times 400$ ).

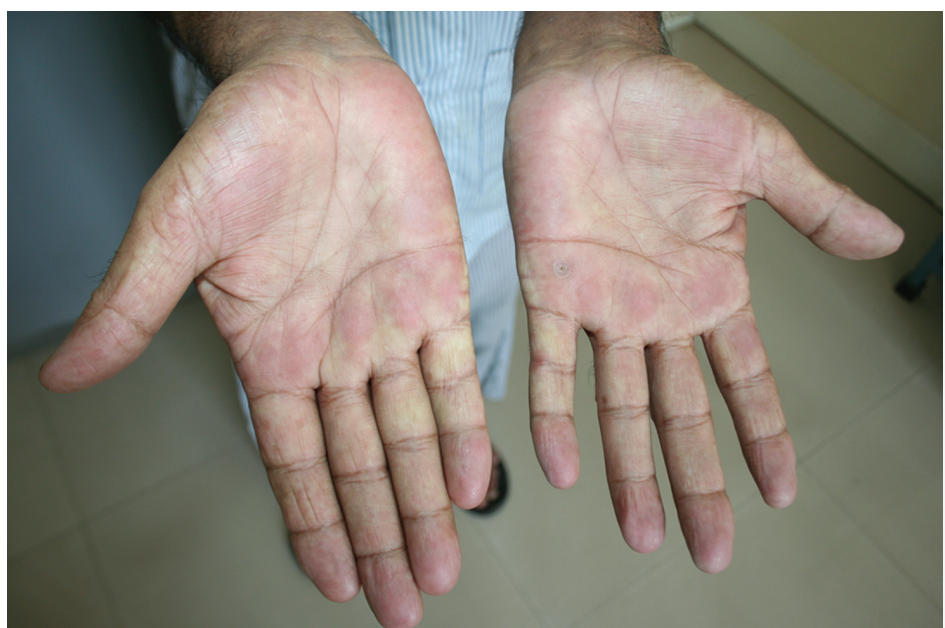

Figure 1. Response after 4 weeks of Hydroxy Chloroquin Sulfate. 


\section{Discussion}

Papular form of GA has been reported to be familial. None of the family members of our patient was similarly affected. Although the occurrence of GA on the dorsum of the hands is frequent, involvement of the palms appears to be rare. Only a few cases have been previously reported, most often as painful acral papules [2]. Two pediatric cases of the subcutaneous variant of GA also exist [3]. Of the cases of GA on the palms that we reviewed, one case involved a woman with dermatomyositis who developed a solitary lesion of GA on the palm [4]. Brey et al presented 4 patients with acute onset acral papules of GA, 2 of whom had lesions involving the palm. Two of their 4 patients developed concomitant arthralgias and were evaluated extensively for rheumatologic disease, but were found not to meet criteria for any [5]. Painful lesions of GA on the palm and soles were also noted in three of thirteen patients with GA and lymphoma evaluated in a retrospective study by Barksdale et al, leading the authors to conclude that atypical presentations, such as involvement on the palms and soles, may be associated with an underlying hematopoietic malignancy [6]. Whereas GA has not been consistently linked to systemic disease [7], conditions such as interstitial granulomatous dermatitis with arthritis, palisaded neutrophilic and granulomatous dermatitis, rheumatoid papules, and Churg-Strauss granulomas, which all can clinically and histologically overlap with GA, belong to a spectrum of granulomatous diseases thought to be an immunemediated reaction to a number of underlying conditions, such as rheumatoid arthritis, collagen vascular disease, Wegener granulomatosis, and malignancy. Our patient had no identifiable associated immune-mediated condition at the time of diagnosis or subsequent follow-up. Our patient had slightly tender papules and nodules on palms in contrast to asymptomatic nature of GA elsewhere.

Granulomatous drug reactions have been associated with a number of medications, including calcium channel blockers, ACE inhibitors, beta blockers, antidepressants, and anticonvulsants. These generally manifest with erythematous to violaceous GA-like plaques that characteristically involve the inner aspects of the arms, medial thighs, and intertriginous areas [8] and occur months to years after drug onset [9]. The histologic pattern of interstitial granulomatous drug eruption shares some similarities with that of granuloma annulare. However, interstitial granulomatous drug eruption can be differentiated by the absence of any significant necrobiosis, the presence of vacuolar interface changes, and the variable lymphoid atypia, not seen in granuloma annulare [10]. Our patient was not taking any drugs that had been implicated in granulomatous drug eruptions. In addition clinically \& histopathology does not support a diagnosis of interstitial granulomatous drug reaction our patient.

Although GA is regarded as the prototype of a palisading granulomatous dermatoses, the interstitial and mixed patterns predominate [11]. Our patient also had the interstitial pattern of GA. Abundant dermal mucin is a hallmark of GA. Unique histopathological picture clinched the diagnosis of GA in our patient. GA on palms poses a clinical diagnostic challenge because similar clinical features are shared by many a differential diagnoses. Histopathology is of vital importance for correct diagnosis and treatment. GA should be considered in differential diagnosis of papular lesions on palms.
Our patient was unique as regards unusual age of onset, involvement of unusual site like palms, not being associated with classical lesions of GA elsewhere, skin biopsy findings making the diagnosis of interstitial GA and remarkable initial response to hydroxychloroquin sulphate $400 \mathrm{mg}$ daily after 1 month (Figure 1 and 4 shows pre treatment \& post treatment photograph).

Localized granuloma annulare is self-limited and asymptomatic, treatment usually is not necessary. Systemic therapy is required for disseminated GA. Many other treatments proposed are topical, intralesional and systemic corticosteroids, chloroquine, hydroxychloroquine sulphate, potassium iodide, niacinamide, chlorpropamide, cyclosporine, chlorambucil, etretinate etc.

\section{Conclusion}

This is an unusual presentation of Granuloma annulare on palms because of the late onset, uncommon localization, and absence of classical lesions of GA elsewhere and was uniquely treated with Hydroxychloroquine which led to remission. On review of literatures on few cases of GA on palms were noted whereas few case of disseminated GA treated with Hydroxychloroquine as been published.

Whenever we come across patient presenting with erythematous papules and nodules over the palm, the diagnosis of granuloma annulare should be rule out with considering all differential diagnosis. erythema multiforme, erythema elevatum diutinum, drug reactions, vasculitis / urticarial vasculitis, secondary syphilis, erythromelalgia, sarcoidosis.

\section{REFERENCES}

1. Cunliffe WJ. Necrobiotic disorders, Champion R H, burton J L, Ebling F J G, Eds. Textbook of Dermatology, 5th Edition, 2027-2040. 2. Stewart LR, George S, Hamacher KL, Hsu S. Granuloma annulare on the palms. Dermatol Online J. 2011;17:7.

3. Takeyama J, Sanada T, Watanabe M, Hatori M, Kunikata N, Aiba S. Subcutaneous granuloma annulare in a child's palm: a case report. J Hand Surg Am. 2006;31:103-6.

4. Imamura S, Ohnishi R, Kawasaki Y, Yoshida MJ. Longstanding solitary granuloma annulare on the palm of a patient with dermatomyositis. Dermatol. 2008;35:304-5.

5. Brey NV, Malone J, Callen J. Acute-onset, painful acral granuloma annulare: a report of 4 cases and a discussion of the clinical and histologic spectrum of the disease. Arch Dermatol. 2006;142:49-54. 6. Barkesdale SK, Perniciario C, Halling KC, Strickler JG. Granuloma annulare in patient wth malignant lymphoma: cliniclopathological study of thirteen new cases. J Am Dermatol. 1994;31:42-8.

7. Dahl MV. Granuloma annulare: long-term follow-up. Arch Dermatol. 2007;143:946-7.17. Kroesen S, Itin PH, Hasler P. Arthritis and interstitial granulomatous dermatitis (Ackerman syndrome) with pulmonary silicosis. Semin Arthritis Rheum. 2003;32:33440.

8. Magro CM, Crowson AN, Schapiro BL. The interstitial granulomatous drug reaction: A distinctive clinical and pathological entity. J Cutan Pathol. 1998;25:72-8.

9. Howard A, White CR. Non-infectious Granulomas. 2nd Edition ed. Dermatology, ed. Bolognia. 2007: Elsevier Inc.

10. Weedon D. The granulomatous reaction pattern. 3rd Edition. Weedon's Skin Pathology. 2010: Elsevier Inc.

11. Chaitra V, Inchara YK, Rajalakshmi T. Granuloma annulare - Histology reconsidered. Ind J Dermatol Venereol Leprol. 2010;76:568-69.

Copyright by Snehal Lunge, et al. This is an open access article distributed under the terms of the Creative Commons Attribution License, which permits unrestricted use, distribution, and reproduction in any medium, provided the original author and source are credited. 